\title{
Relating mean blood glucose and glucose variability to the risk of multiple episodes of hypoglycaemia in type 1 diabetes
}

\author{
E. S. Kilpatrick • A. S. Rigby $\cdot$ K. Goode $\cdot$ S. L. Atkin
}

Received: 30 March 2007 / Accepted: 6 August 2007 / Published online: 19 September 2007

(C) Springer-Verlag 2007

\begin{abstract}
Aims/hypothesis The main disadvantage of intensive treatment in the Diabetes Control and Complications Trial (DCCT) was an increased risk of hypoglycaemia that was not explained by the difference in $\mathrm{HbA}_{1 \mathrm{c}}$ values alone. This study re-analysed DCCT data to establish whether mean blood glucose (MBG) and/or glucose variability add to the predictive value of $\mathrm{HbA}_{1 \mathrm{c}}$ for hypoglycaemia risk in type 1 diabetes.

Methods The times to first and subsequent severe hypoglycaemic events were compared with $\mathrm{MBG}, \mathrm{HbA}_{1 \mathrm{c}}$ and withinday SD of blood glucose using Cox regression after adjusting for other known risk factors for hypoglycaemia.

Results On its own, the incidence of time to first hypoglycaemic event increased 1.05-fold for each $1 \mathrm{mmol} / \mathrm{l}$ decrease in MBG and 1.07-fold for every $1 \mathrm{mmol} / \mathrm{l}$ increase in glucose SD. MBG and SD of blood glucose also both added to the ability of $\mathrm{HbA}_{1 \mathrm{c}}$ to predict repeated hypoglycaemic events: after adjusting for $\mathrm{HbA}_{1 \mathrm{c}}$, a $1 \mathrm{mmol} / \mathrm{l}$ increase in $\mathrm{SD}$ was associated with a 1.09-fold increased risk of a first event, increasing to a 1.12 -fold risk of a fifth event. A $1 \mathrm{mmol} / \mathrm{l}$ fall in MBG added a constant 1.02-1.03-fold risk of repeated
\end{abstract}

E. S. Kilpatrick $(\square)$

Department of Clinical Biochemistry, Hull Royal Infirmary,

Anlaby Road,

Hull HU3 2JZ, UK

e-mail: Eric.Kilpatrick@hey.nhs.uk

\section{A. S. Rigby $\cdot$ K. Goode}

Academic Department of Cardiology, University of Hull, Hull, UK

S. L. Atkin

Department of Diabetes, Hull York Medical School,

Hull, UK events. Daytime events were predicted more accurately than nocturnal episodes.

Conclusions/interpretation This study has established that $\mathrm{HbA}_{1 \mathrm{c}}, \mathrm{MBG}$ and glucose variability measurements each have an independent role in determining an individual's risk of hypoglycaemia in type 1 diabetes. All three aspects of glycaemic assessment should thus be considered in patients in whom hypoglycaemia is a real or potential problem.

Keywords DCCT · Diabetes · Glucose - Glucose variability Glycated haemoglobin $\cdot \mathrm{HbA}_{1 \mathrm{c}} \cdot$ Hypoglycaemia
Abbreviations
HR hazard ratio
MBG mean blood glucose

\section{Introduction}

Having established $\mathrm{HbA}_{1 \mathrm{c}}$ as a measure of prior glycaemia [1], both the DCCT (in type 1 diabetes) and the UK Prospective Diabetes Study (in type 2 diabetes) confirmed an exponential relationship between rising blood glucose and the risk of either developing or worsening retinopathy, nephropathy and neuropathy [2-5]. The challenge was then to try and keep as many patients with diabetes as close to near-normal glycaemia as possible [6].

The DCCT also gave an insight into the factors that prevented this goal in type 1 diabetes. They found that as the $\mathrm{HbA}_{1 \mathrm{c}}$ of a patient fell, the risk of having an episode of severe hypoglycaemia increased in an apparently exponential manner [2]. Thus, were it not for this barrier of hypoglycaemia, people with diabetes could have normal $\mathrm{HbA}_{1 \mathrm{c}}$ levels over a lifetime of diabetes [7]. Indeed, 
hypoglycaemia remains a very significant cause of physical morbidity [8] and mortality [9] in patients with type 1 diabetes. Additionally, psychological, quality-of-life, driving and employment issues may be associated with recurrent episodes $[7,10]$.

Closer examination of the DCCT data showed that there were several other risk factors associated with hypoglycaemia risk such as a history of prior episodes [11]. They also established that the relationship between $\mathrm{HbA}_{1 \mathrm{c}}$ and hypoglycaemia was not as straightforward as originally reported. For example, the threefold higher risk of hypoglycaemia associated with intensive treatment compared with conventional treatment was in excess of what would have been predicted simply from the differences in $\mathrm{HbA}_{1 \mathrm{c}}$ between the two groups. Thus, even when patients from each group had the same $\mathrm{HbA}_{1 \mathrm{c}}$ value, there remained an unexplained increase in risk associated with being treated intensively [11].

As well as providing data on hypoglycaemia and risk of complications, the DCCT also provided the best evidence of the relationship between glucose and $\mathrm{HbA}_{1 \mathrm{c}}$. However, in doing so, it has also shown that patients with the same mean (AUC) blood glucose (MBG) can have quite different $\mathrm{HbA}_{1 \mathrm{c}}$ values and vice versa [12]. The analysis was made possible because of the laboratory measurement of sevenpoint glucose profiles over a $24 \mathrm{~h}$ period (taken pre- and postprandially) every 3 months throughout the trial.

Since it is purely low blood glucose values that lead to hypoglycaemia, rather than low $\mathrm{HbA}_{1 \mathrm{c}}$ readings per se [13], this current study re-examined the DCCT data to determine whether both MBG and glucose variability can add to the ability of $\mathrm{HbA}_{1 \mathrm{c}}$ to predict hypoglycaemia risk.

\section{Methods}

The datasets We used the publicly accessible datasets collected by the DCCT, which are stored in SAS format (http://www.gcrc.umn.edu/gcrc/downloads.html, last accessed in August 2007). The DCCT was a 9 year follow-up study of 1,441 participants with type 1 diabetes comparing the effect of intensive vs conventional blood glucose management on the development of the microvascular complications of diabetes. At randomisation patients were stratified into one of two cohorts. The primary prevention cohort $(n=726)$ had no evidence of retinopathy by fundus photography and a urinary AER of $<40 \mathrm{mg} / 24 \mathrm{~h}(28 \mu \mathrm{g} / \mathrm{min})$. The secondary prevention cohort $(n=715)$ had only minimal retinopathy and an AER of $<200 \mathrm{mg} / 24 \mathrm{~h}(140 \mu \mathrm{g} / \mathrm{min})$. The study participants were randomised into intensive $(n=711)$ and conventional $(n=730)$ treatment groups.

Definition of hypoglycaemia Severe hypoglycaemia was defined as an episode in which a patient required the assistance of another person (a doctor or someone else) and which was associated with a blood glucose level of $<2.78 \mathrm{mmol} / 1 \quad(<50 \mathrm{mg} / \mathrm{dl})$ or prompt recovery following intravenous glucose, glucagon or oral carbohydrate [11]. Information recorded about the episode included date, time, place, symptoms and contributing factors including changes in diet, exercise, insulin dose and associated accidents and injuries. Only about $80 \%$ of all episodes had reports with most of these data collected [14]. We therefore used this more robust dataset, accessible as the SAS dataset f0922. ssd01, in the analysis. Basic epidemiological data have been reported elsewhere [1]. In brief, just under $50 \%$ of all patients $(n=714)$ developed at least one episode of hypoglycaemia. Of these, $65 \%$ were in the intensive group while $35 \%$ were in the conventional group. During a typical year, approximately $27 \%$ of patients in the intensive and $10 \%$ in conventional groups had at least one episode of hypoglycaemia.

Glycaemic variables Quarterly measurements of $\mathrm{HbA}_{1 \mathrm{c}}$ and blood glucose profiles were analysed. Blood glucose was assessed at seven points throughout the day, namely prebreakfast (assumed time 0700 hours), post-breakfast (0830 hours), pre-lunch (1200 hours), post-lunch (1330 hours), pre-supper (1800 hours), post-supper (1930 hours) and bedtime (2200 hours). An additional data point was collected at 0300 hours, but since this was measured in $<1 \%$ of occasions, it was not considered further. Mean blood glucose (MBG) was calculated by the AUC method using the trapezoidal rule [15]. This was performed as for Rohlfing et al. [12], with the exception that rather than assuming a constant blood glucose between bedtime and morning, we assumed the following morning glucose value to be the same as that of the previous morning. A separate analysis using exactly the Rohlfing method gave similar results (data not presented). Instability of blood glucose (within-day standard deviation) was calculated as the SD of daily blood glucose around the mean from each quarterly visit [16]. We also calculated variability using the MAGE statistic [17]. MAGE is the mean of the absolute values of fluctuations ( $>1 \mathrm{SD}$ of the mean blood glucose value) between consecutive blood glucose readings and measures the day's largest glycaemic excursion.

As many patients prefer to perform four-point glucose profiles (dispensing with postprandial measurements), we also repeated the exercise using just pre-meal and bedtime readings and also looking at individual glucose time points.

Compliance with blood glucose measurement Not every patient had a complete blood glucose profile for every quarter of his/her participation. Table 1 shows the compliance of patients throughout the study period. Patients were 
Table 1 Compliance with glucose profile testing in each quarter of the DCCT

\begin{tabular}{|c|c|c|c|c|c|c|c|c|c|c|}
\hline \multirow{2}{*}{$\begin{array}{l}\text { Quarter } \\
\text { of } \\
\text { study }\end{array}$} & \multicolumn{8}{|c|}{$\begin{array}{l}\text { Number of glucose profile samples } \\
\text { collected }\end{array}$} & \multirow[t]{2}{*}{$\begin{array}{l}\text { Total } \\
\text { patients }\end{array}$} & \multirow[t]{2}{*}{$\begin{array}{l}\text { Compliance } \\
(\%)^{\mathrm{a}}\end{array}$} \\
\hline & 0 & 1 & 2 & 3 & 4 & 5 & 6 & 7 & & \\
\hline B & 19 & 1 & 1 & 4 & 7 & 33 & 202 & 1,174 & 1,441 & 97 \\
\hline 1 & 48 & 1 & 2 & 2 & 13 & 52 & 210 & 1,113 & 1,441 & 95 \\
\hline 2 & 51 & 3 & 0 & 3 & 10 & 51 & 254 & 1,068 & 1,440 & 95 \\
\hline 3 & 54 & 1 & 1 & 7 & 19 & 43 & 275 & 1,038 & 1,438 & 94 \\
\hline 4 & 51 & 1 & 1 & 8 & 21 & 40 & 233 & 1,081 & 1,436 & 94 \\
\hline 5 & 94 & 0 & 5 & 5 & 14 & 61 & 227 & 1,029 & 1,435 & 91 \\
\hline 6 & 93 & 0 & 2 & 7 & 15 & 59 & 248 & 1,011 & 1,435 & 91 \\
\hline 7 & 87 & 0 & 2 & 3 & 20 & 57 & 277 & 987 & 1,433 & 92 \\
\hline 8 & 50 & 1 & 1 & 2 & 14 & 43 & 265 & 1,056 & 1,432 & 95 \\
\hline 9 & 115 & 2 & 2 & 2 & 16 & 63 & 251 & 976 & 1,427 & 90 \\
\hline 10 & 98 & 1 & 1 & 4 & 17 & 58 & 212 & 1,034 & 1,425 & 91 \\
\hline 11 & 116 & 1 & 4 & 3 & 12 & 56 & 231 & 1,001 & 1,424 & 90 \\
\hline 12 & 83 & 1 & 2 & 8 & 16 & 55 & 258 & 1,000 & 1,423 & 92 \\
\hline 13 & 126 & 2 & 3 & 5 & 18 & 54 & 232 & 984 & 1,424 & 89 \\
\hline 14 & 131 & 2 & 4 & 6 & 8 & 61 & 250 & 961 & 1,423 & 89 \\
\hline 15 & 159 & 1 & 5 & 6 & 18 & 67 & 202 & 963 & 1,421 & 86 \\
\hline 16 & 120 & 0 & 3 & 5 & 15 & 58 & 188 & 991 & 1,380 & 89 \\
\hline 17 & 181 & 1 & 3 & 5 & 7 & 55 & 209 & 870 & 1,331 & 85 \\
\hline 18 & 139 & 2 & 6 & 6 & 13 & 42 & 187 & 886 & 1,281 & 87 \\
\hline 19 & 163 & 1 & 4 & 3 & 16 & 43 & 185 & 801 & 1,216 & 84 \\
\hline 20 & 123 & 0 & 2 & 6 & 11 & 28 & 167 & 802 & 1,139 & 87 \\
\hline 21 & 183 & 1 & 0 & 4 & 10 & 36 & 154 & 660 & 1,048 & 81 \\
\hline 22 & 173 & 0 & 0 & 4 & 9 & 36 & 132 & 598 & 952 & 80 \\
\hline 23 & 146 & 0 & 1 & 3 & 13 & 28 & 100 & 548 & 839 & 80 \\
\hline 24 & 111 & 0 & 2 & 5 & 4 & 31 & 115 & 499 & 767 & 84 \\
\hline 25 & 136 & 0 & 1 & 3 & 4 & 32 & 116 & 385 & 677 & 78 \\
\hline 26 & 112 & 1 & 0 & 4 & 10 & 20 & 79 & 384 & 610 & 79 \\
\hline 27 & 123 & 0 & 0 & 3 & 6 & 18 & 63 & 317 & 530 & 75 \\
\hline 28 & 73 & 0 & 0 & 2 & 2 & 19 & 55 & 296 & 447 & 82 \\
\hline 29 & 81 & 1 & 1 & 4 & 2 & 13 & 51 & 247 & 400 & 77 \\
\hline 30 & 74 & 1 & 0 & 2 & 2 & 15 & 43 & 223 & 360 & 78 \\
\hline 31 & 66 & 0 & 0 & 1 & 2 & 18 & 47 & 174 & 308 & 77 \\
\hline 32 & 39 & 0 & 0 & 1 & 5 & 9 & 31 & 191 & 276 & 83 \\
\hline 33 & 59 & 0 & 0 & 2 & 2 & 8 & 32 & 168 & 271 & 76 \\
\hline 34 & 49 & 0 & 0 & 3 & 2 & 16 & 35 & 165 & 270 & 80 \\
\hline 35 & 53 & 0 & 0 & 0 & 0 & 11 & 37 & 168 & 269 & 80 \\
\hline 36 & 34 & 0 & 0 & 0 & 1 & 4 & 31 & 198 & 268 & 86 \\
\hline
\end{tabular}

$B$ Baseline

${ }^{\mathrm{a}} 5$ or more tests

assumed to be still in the study if they had their $\mathrm{HbA}_{1 \mathrm{c}}$ assessed at the same time as the glucose profile or in any of the subsequent three quarters. For those with any six readings we dealt with the single missing data point as follows. If the missing value occurred between any two data points, we assumed that the actual value lay on a straight line between these points [18]. We adopted a similar process for any five readings. We did not estimate the AUC, if three or more observations were missing. We are aware that many methods can be used to extrapolate missing values for longitudinal data and that each method has its advantages and disadvantages, depending on the setting.

For the analysis using just pre-meal and bedtime values, we limited the profiles to those in which all four specimens were collected. With regard to the accuracy of MBG assessment by this method, a glucose profile with only four points has previously been found to be highly correlated $(r=0.91)$ to profiles taken using continuous glucose monitoring [19].

Hypoglycaemia risk and statistical methods The relationship between the variables and the risk of hypoglycaemia was investigated by Cox regression, from which hazard ratios (HRs) and 95\% CIs were calculated. All the glucose profiles that met the criteria described above and $\mathrm{HbA}_{1 \mathrm{c}}$ values collected from each individual were used, not just the value that preceded a hypoglycaemic event. A separate analysis looked at whether the variables predicted daytime hypoglycaemia episodes (0700-2200 hours) any differently to nocturnal ones. The Cox regression model is semiparametric in that no assumption concerning event-free survival times is necessary. The assumption of proportionality of the Cox model covariates was tested by residual plotting $[20,21]$. Each variable (MBG AUC, SD MBG [within-day], MAGE and $\mathrm{HbA}_{1 \mathrm{c}}$ ) was considered as a timedependent variable within the Cox model structure such that the respective means of each was updated continuously during follow-up using the most recent value. $\mathrm{HbA}_{1 \mathrm{c}}$ was measured monthly in the intensive group, otherwise quarterly, with the time-dependent covariate for this variable being adjusted accordingly. All Cox models were adjusted for the following baseline covariates: age (years), sex, disease duration (months), randomisation treatment (conventional vs intensive), prevention cohort (primary vs secondary), study phase (first or second), prior history of hypoglycaemia (none vs any) and stimulated C-peptide level (nmol/l). The GLIM4 (available from http://www.nag. com/stats/gdge_soft.asp, last accessed in August 2007) [22] and SPSS (version 11; SPSS, Chicago, IL, USA) statistical computer packages were used to analyse the data. An arbitrary level of $5 \%$ statistical significance (two-tailed) was assumed.

Repeated hypoglycaemic events We used conditional models to analyse the repeated failure times. These models are widely used because of their flexibility and ease of analysis [23]. A convenient feature is that separate analyses are carried out for each successive level of hypoglycaemia (at least one, two, three episodes and so on). It is also easy to model the preceding failure time. Our models do not take into account competing risks, e.g. death, as such models are difficult to interpret and extensions to repeated failure times 
are statistically very complex [23, 24]. The goodness-of-fit for each model was assessed by calculating an $r^{2}$ equivalent $\left(r^{2}\right.$ is the proportion of explained variation) based on the difference between the likelihood ratio of the fitted model and the likelihood ratio of the null model (i.e. the model of no covariates) [25].

Model validation To address this, we generated 50 bootstrap samples from the original database (bootstrapping is resampling with replacement). On each bootstrapped sample we fitted the same models as for the original dataset up to and including models for five hypoglycaemic episodes.

Bootstrapping is not without its critics. Between 1989 and 2000 over 1,000 publications addressed theoretical issues surrounding re-sampling methods [26]. For example, what makes bootstrapping difficult for the Cox model is censoring, the very thing that makes survival data unique [27], and concerns remain that the theoretical basis for re-sampling is not fully developed [28]. Nevertheless, this technique can still be helpful in validating this sort of model.

\section{Results}

There were completed reports documenting 3,103 episodes of hypoglycaemia in 655 patients. The median number of episodes was three (interquartile range 1-6); one patient had 42 episodes. $\mathrm{HbA}_{1 \mathrm{c}}$ and MBG values in the study have been documented elsewhere [2]. The median SD in the study was $4.0 \mathrm{mmol} / 1$ (2.5th-97.5th centiles, $2.4-6.1 \mathrm{mmol} / \mathrm{l})$. In the intensively treated group alone it was $3.6 \mathrm{mmol} / \mathrm{l}(2.5$ th97.5th centiles, $2.3-5.5 \mathrm{mmol} / \mathrm{l}$ ) and in the conventionally treated group $4.5 \mathrm{mmol} / 1(2.5-6.4 ; p<0.001$ using the MannWhitney $U$ test).

Effect of baseline covariates Table 2 shows the effect sizes for the baseline confounders, which are similar to those reported in detail elsewhere [11]. The HRs are univariate since this makes them easier to compare with others and not everyone adjusts for the same confounders. The largest influence on hypoglycaemia was intervention group (intensive vs conventional treatment), with the second strongest influence being prior hypoglycaemia.

Table 3 describes the risk of hypoglycaemia and the relative risk of intensive vs conventional treatment within baseline tertiles of glucose SD and tertiles of MBG (AUC). The total person-years exposure was 9,508 years (4732 intensive group). Due to rounding errors, these figures may differ slightly from those reported by the DCCT. The relative risk (intensive vs conventional treatment) for baseline MBG increased by increasing MBG tertile while the reverse was true for baseline SD.
Effect of $M B G$ and glucose variability Figure 1 shows the event rate according to tertile of glucose variability. Multivariate Cox regression, without reference to $\mathrm{HbA}_{1 \mathrm{c}}$, showed that both MBG and within-day SD were independently predictive of the time-to-first severe hypoglycaemic event (HR for MBG 0.95, 95\% CI 0.92-0.97, $p<0.0001$; HR for SD 1.07, 95\% CI 1.02-1.12, $p=0.004$ ).

Table 4 shows the association between MBG and withinday SD and the development of one or more severe hypoglycaemic episodes after adjustment for $\mathrm{HbA}_{1 \mathrm{c}}$. It shows that both MBG and SD independently added to the ability of $\mathrm{HbA}_{1 \mathrm{c}}$ to predict hypoglycaemia. For the SD, there was a dose-response trend such that as the number of hypoglycaemia episodes increased so did the HR for SD. The reduction in statistical significance as the number of episodes increased is presumably a function of reducing sample size. In comparison, MBG showed a more constant HR with increasing numbers of episodes. With regard to SD, $40(80 \%)$ of the bootstrapped samples showed that the HR for five hypoglycaemic episodes was higher than that for one. Table 5 shows the HRs for the first ten bootstrapped samples, indicating a confirmation of the doseresponse effect. The proportion of explained variation for models based on one, two, three, four and five episodes was 2.1, 2.6, 3.6, 4.0 and $4.4 \%$, respectively. The low amount of explained variation is in line with findings obtained by different methods [11].

Mean blood glucose and glucose variability remained independently predictive of hypoglycaemia even after limiting the analysis to four-point pre-meal and bedtime values (HR for MBG 0.97, 95\% CI 0.95-0.99, $p=0.008$; HR for glucose SD 1.09, 95\% CI 1.05-1.14, when looking at one or more episodes).

There were 1,569 nocturnal (1000-0659 hours) hypoglycaemic episodes and 1,145 daytime episodes; with 389 episodes the time was not reported. Both mean glucose and glucose variability were better predictors of daytime rather than night-time episodes of hypoglycaemia (Table 6). The degree of variability in each of the glucose time points was predictive of daytime hypoglycaemia, but only the variability in these at the start and towards the end of the day were predictive of nocturnal episodes.

Inclusion of previous failure time in the models [23] made little difference to the HRs. Likewise, restricting analysis to just seven-point glucose profiles made no difference to our findings.

The relationship between MAGE and hypoglycaemia was generally smaller in magnitude and statistical significance than with SD. For example, the HR (adjusted as in Table 4) remained constant at 1.03 between the first and fourth hypoglycaemic episode $(p=0.006$ and $p=0.17$ for first and fourth episodes, respectively). The natural log of SD was unrelated to hypoglycaemia risk. 
Table 2 Effect size of baseline confounders for one or more severe hypoglycaemic episodes

\begin{tabular}{|c|c|c|c|c|c|c|c|c|c|c|}
\hline \multirow[t]{3}{*}{ Variable } & \multicolumn{10}{|c|}{ Number of hypoglycaemic episodes } \\
\hline & \multicolumn{2}{|l|}{1} & \multicolumn{2}{|l|}{2} & \multicolumn{2}{|l|}{3} & \multicolumn{2}{|l|}{4} & \multicolumn{2}{|l|}{5} \\
\hline & HR & $\begin{array}{l}p \\
\text { value }\end{array}$ & HR & $\begin{array}{l}p \\
\text { value }\end{array}$ & HR & $\begin{array}{l}p \\
\text { value }\end{array}$ & HR & $\begin{array}{l}p \\
\text { value }\end{array}$ & HR & $\begin{array}{l}p \\
\text { value }\end{array}$ \\
\hline Age (years) & 0.99 & 0.097 & 0.98 & 0.01 & 0.98 & 0.002 & 0.97 & 0.002 & 0.97 & 0.003 \\
\hline C-peptide $(<0.2$ vs $\geq 0.2 \mathrm{nmol} / \mathrm{l})$ & 1.002 & 0.51 & 0.998 & 0.54 & 0.997 & 0.42 & 0.998 & 0.58 & 0.998 & 0.67 \\
\hline Duration of diabetes & 1.002 & 0.03 & 1.003 & 0.002 & 1.003 & 0.001 & 1.004 & 0.002 & 1.003 & 0.008 \\
\hline $\mathrm{HbA}_{1 \mathrm{c}}$ & 0.93 & $<0.001$ & 0.93 & $<0.001$ & 0.93 & $<0.001$ & 0.92 & $<0.001$ & 0.92 & $<0.001$ \\
\hline Insulin dose $(\mathrm{U} / \mathrm{kg})$ & 1.42 & 0.01 & 1.84 & $<0.001$ & 2.09 & $<0.001$ & 2.17 & $<0.001$ & 2.52 & $<0.001$ \\
\hline Intervention & 1.22 & 0.012 & 1.33 & 0.003 & 1.4 & 0.002 & 1.42 & 0.004 & 1.36 & 0.24 \\
\hline Recruitment phase & 1.47 & $<0.001$ & 1.2 & 0.12 & 1.06 & 0.63 & 1.01 & 0.97 & 0.96 & 0.8 \\
\hline Prior severe hypoglycaemia & 1.98 & $<0.001$ & 2.27 & $<0.001$ & 2.36 & $<0.001$ & 2.31 & $<0.001$ & 2.64 & $<0.001$ \\
\hline $\begin{array}{l}\text { Randomisation group (intensive vs } \\
\text { conventional) }\end{array}$ & 2.28 & $<0.001$ & 2.56 & $<0.001$ & 4 & $<0.001$ & 4.54 & $<0.001$ & 4.59 & $<0.001$ \\
\hline Sex (male vs female) & 0.98 & 0.81 & 1.01 & 0.81 & 1.14 & 0.23 & 1.15 & 0.24 & 1.08 & 0.57 \\
\hline
\end{tabular}

\section{Discussion}

This study has shown that both the MBG and the glucose variability of a patient with type 1 diabetes independently add to the ability of $\mathrm{HbA}_{1 \mathrm{c}}$ to predict the risk of hypoglycaemia. When looked at without reference to $\mathrm{HbA}_{1 \mathrm{c}}$, we found that a $1 \mathrm{mmol} / \mathrm{l}$ rise in $\mathrm{MBG}$ was associated with a 1.05 -fold reduction in risk of first severe hypoglycaemic episode while a $1 \mathrm{mmol} / \mathrm{l}$ increase in the daily SD of blood glucose led to a 1.07 -fold rise in risk. When looking at repeated episodes of hypoglycaemia, both MBG and SD of blood glucose predicted hypoglycaemia independently of $\mathrm{HbA}_{1 \mathrm{c}}$, with the magnitude of the SD effect increasing among patients with the largest number of events. Assuming most patients with type 1 diabetes are now treated similarly to the intensively treated DCCT

Table 3 Subgroup analyses of hypoglycaemia by baseline tertiles (lowest to highest) of SD and baseline tertiles of MBG (AUC)

\begin{tabular}{|c|c|c|c|c|c|}
\hline \multirow{2}{*}{$\begin{array}{l}\text { Baseline } \\
\text { characteristic }\end{array}$} & \multicolumn{2}{|c|}{ Conventional } & \multicolumn{3}{|l|}{ Intensive } \\
\hline & $\begin{array}{l}\text { Episodes/ } \\
\text { PY }\end{array}$ & Rate & $\begin{array}{l}\text { Episodes/ } \\
\text { PY }\end{array}$ & Rate & RR \\
\hline \multicolumn{6}{|l|}{ SD in tertiles } \\
\hline $1 \mathrm{st}$ & $184 / 1605$ & 11.5 & $702 / 1613$ & 43.5 & 3.8 \\
\hline $2 \mathrm{nd}$ & $202 / 1495$ & 13.5 & $725 / 1646$ & 44.1 & 3.3 \\
\hline $3 \mathrm{rd}$ & $348 / 1674$ & 20.8 & $942 / 1472$ & 64.0 & 3.1 \\
\hline \multicolumn{6}{|c|}{ MBG(AUC) in tertiles } \\
\hline $1 \mathrm{st}$ & $265 / 1501$ & 17.7 & $749 / 1627$ & 46.0 & 2.6 \\
\hline 2 nd & $268 / 1746$ & 15.3 & $781 / 1441$ & 55.4 & 3.6 \\
\hline $3 \mathrm{rd}$ & $201 / 1526$ & 13.2 & $859 / 1694$ & 50.7 & 3.8 \\
\hline
\end{tabular}

$R R$ Relative risk of intensive vs conventional treatment, $P Y$ personyears of exposure group, the above finding means that if two patients have identical $\mathrm{HbA}_{1 \mathrm{c}}$ and $\mathrm{MBG}$ values, but one has glucose variability at the 97.5 th rather the 2.5 th centile of the population, this patient will have a $35-45 \%$ excess of risk of one or more severe hypoglycaemic episodes. Although this means that the markers of glycaemia studied here are still not one of the main predictors of hypoglycaemic risk [11], they certainly add to the predictive value of $\mathrm{HbA}_{1 \mathrm{c}}$ alone. Further examination of baseline tertiles of MBG and SD showed that the excess risk of hypoglycaemia associated with intensive treatment compared with conventional was most marked among patients in their respective highest tertile of MBG, which is consistent with a previous analysis using $\mathrm{HbA}_{1 \mathrm{c}}$ values at the start of the trial [11]. This effect persisted throughout the study (Fig. 1).

Perhaps predictably, these overall findings relating to any episode of severe hypoglycaemia conceal the fact that the daytime blood glucose measurements were much more likely to predict daytime rather than night-time events. In fact, it was only glucose variability and not the mean of glucose values at both ends of the day that predicted nocturnal hypoglycaemia. In this respect, it means that patients who aim to run their blood glucoses higher at bedtime in order to prevent hypoglycaemia may be better advised to aim to reduce their glycaemic fluctuations instead.

All our findings related to glucose variability are actually in contrast to a previous analysis of the DCCT dataset, which showed that variability in blood glucose around any given mean value exerts little additional influence on the risk of microvascular complications [29]. However, given the fact that hypoglycaemia is a complication solely due to acute glycopenia, it is perhaps not surprising that in this case both MBG and glucose variability were independently 


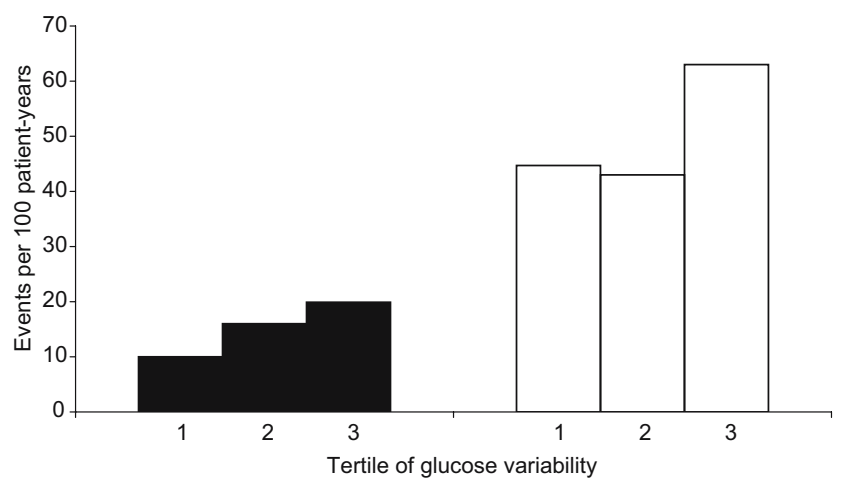

Fig. 1 Rate of hypoglycaemia in the DCCT treatment groups (conventional, closed bars; intensive, open bars) according to tertiles of glucose variability (SD) throughout the study

related to hypoglycaemia, a fact pointed out by an editorial that accompanied the previously reported results [30]. The ability of $\mathrm{HbA}_{1 \mathrm{c}}$ itself to independently predict severe hypoglycaemia risk is somewhat peculiar to the DCCT and may be related to the exclusion criteria of that study (see below). In more unselected cohorts of patients with type 1 diabetes this has not proved to be the risk marker that it has been shown to be here $[8,31,32]$.

In showing that increased glucose variability leads to an increased risk of hypoglycaemia, it seems paradoxical that severe hypoglycaemia was more frequent in the intensively treated patients than in the conventionally treated ones for every level of $\mathrm{HbA}_{1 \mathrm{c}}$ given our finding that the former group had the lower glucose variability (within-day SD 3.6 vs $4.5 \mathrm{mmol} / \mathrm{l})$. There are two possible explanations for this. The first is that the glucose variability (SD) of patients tended to rise as the MBG rose in the DCCT $(r=0.59$, data not shown). As the MBG was higher in the conventionally treated group, it is only to be expected that their glucose

Table 4 Cox regression models relating MBG and blood glucose variability to one or more episodes of severe hypoglycaemia

\begin{tabular}{|c|c|c|c|c|}
\hline \multirow[b]{2}{*}{$\begin{array}{l}\text { Episodes } \\
(n)\end{array}$} & \multicolumn{2}{|l|}{ MBG } & \multicolumn{2}{|l|}{ SD } \\
\hline & $\begin{array}{l}\text { HR } \\
(95 \% \mathrm{CI})\end{array}$ & $\begin{array}{l}p \\
\text { value }\end{array}$ & $\begin{array}{l}\text { HR } \\
(95 \% \mathrm{CI})\end{array}$ & $\begin{array}{l}p \\
\text { value }\end{array}$ \\
\hline 1 & $0.98(0.96-0.99)$ & 0.011 & $1.09(1.04-1.14)$ & 0.001 \\
\hline 2 & $0.98(0.96-1.00)$ & 0.076 & $1.10(1.04-1.16)$ & 0.001 \\
\hline 3 & $0.97(0.94-0.99)$ & 0.039 & $1.11(1.06-1.18)$ & 0.001 \\
\hline 4 & $0.97(0.94-1.00)$ & 0.065 & $1.12(1.04-1.20)$ & 0.002 \\
\hline 5 & $0.97(0.93-1.00)$ & 0.050 & $1.12(1.04-1.21)$ & 0.004 \\
\hline
\end{tabular}

Model adjusted for the following baseline covariates: age (years), sex, disease duration (months), randomisation treatment (conventional vs intensive), prevention cohort (primary vs secondary), prior history of hypoglycaemia (none vs any) and stimulated C-peptide level (nmol/l). Further adjustment was made for $\mathrm{HbA}_{1 \mathrm{c}}$ and either MBG (AUC) (in the case of SD) or SD (in the case of MBG), each as time-dependent covariates variability would also be higher. However, as the present analysis adjusted for both the treatment group and MBG, it was able to establish that an effect of glucose variability on hypoglycaemia risk is both present and independent of both these variables. Second, a recent analysis of DCCT data has shown that the relationship between $\mathrm{MBG}$ and $\mathrm{HbA}_{1 \mathrm{c}}$ was actually different between the treatment groups, with MBG concentrations among intensively treated patients being $1.6 \mathrm{mmol} / 1$ lower at $7 \% \mathrm{HbA}_{1 \mathrm{c}}$ and $2.8 \mathrm{mmol} / \mathrm{l}$ lower at $11 \% \mathrm{HbA}_{1 \mathrm{c}}$ [33]. This would therefore help explain why intensive treatment seemed intrinsically linked to both an increased risk of hypoglycaemia and reduced risk of microvascular complications at the same $\mathrm{HbA}_{1 \mathrm{c}}$ : blood glucose of patients in the intensive arm was simply lower at the same $\mathrm{HbA}_{1 \mathrm{c}}$.

This study is not without its limitations with regard to the extrapolation of findings to all patients with type 1 diabetes. First and foremost is the fact that patients with previous severe hypoglycaemia in the 2 years before recruitment or who did not have warning symptoms of hypoglycaemia were specifically excluded from participating in the DCCT [11]. Indeed, it has been estimated that only $20 \%$ of the general population of patients with type 1 diabetes would meet the selection criteria of DCCT and that this fraction of patients only accounts for 5 to $6 \%$ of all events of severe hypoglycaemia [34]. Second, the glucose profiling was only performed quarterly (which is much more infrequent than would usually be the case) and not every patient collected glucose samples at seven points on every occasion. Also, it is possible that the distribution of patient glucose values could be better served by a marker of variability other than the standard deviation used here, although it appears that the examples of MAGE and log SD are probably worse than SD in this respect.

Table 5 Model validation of HRs for SD using the first ten bootstrapped samples

\begin{tabular}{llllll}
\hline \multirow{2}{*}{ Model } & \multicolumn{5}{l}{ HRs for different episodes of hypoglycaemia } \\
\cline { 2 - 6 } & 1 & 2 & 3 & 4 & 5 \\
\hline 1 & 1.09 & 1.09 & 1.09 & 1.11 & 1.12 \\
2 & 1.08 & 1.08 & 1.09 & 1.10 & 1.10 \\
3 & 1.06 & 1.06 & 1.07 & 1.09 & 1.09 \\
4 & 1.09 & 1.09 & 1.12 & 1.11 & 1.11 \\
5 & 1.11 & 1.11 & 1.12 & 1.18 & 1.17 \\
6 & 1.13 & 1.15 & 1.17 & 1.16 & 1.21 \\
7 & 1.08 & 1.06 & 1.06 & 1.07 & 1.10 \\
8 & 1.09 & 1.07 & 1.09 & 1.09 & 1.09 \\
9 & 1.08 & 1.13 & 1.14 & 1.14 & 1.12 \\
10 & 1.07 & 1.06 & 1.06 & 1.05 & 1.05 \\
\hline
\end{tabular}

Adjustment as in Table 4 
Table 6 Cox regression models relating MBG and blood glucose variability, overall and at individual time points, to one or more episodes of daytime or night-time severe hypoglycaemia

\begin{tabular}{|c|c|c|c|c|c|c|}
\hline \multirow[t]{2}{*}{ Variable } & \multicolumn{3}{|c|}{ Daytime } & \multicolumn{3}{|c|}{ Nocturnal } \\
\hline & HR & $(95 \% \mathrm{CI})$ & $p$ value & HR & $(95 \% \mathrm{CI})$ & $p$ value \\
\hline \multicolumn{7}{|l|}{ Overall } \\
\hline MBG (AUC) & 0.98 & $(0.96-1.00)$ & 0.077 & 0.95 & $(0.91-1.03)$ & 0.95 \\
\hline SD MBG & 1.12 & $(1.06-1.18)$ & $<0.001$ & 1.06 & $(0.99-1.14)$ & 0.076 \\
\hline \multicolumn{7}{|c|}{ Individual time points } \\
\hline \multicolumn{7}{|c|}{ Pre-breakfast } \\
\hline MBG & 0.98 & $(0.96-0.99)$ & 0.033 & 0.99 & $(0.97-1.02)$ & 0.46 \\
\hline SD MBG & 1.12 & $(1.06-1.18)$ & $<0.001$ & 1.07 & $(1.01-1.14)$ & 0.03 \\
\hline \multicolumn{7}{|l|}{ Post-breakfast } \\
\hline MBG & 0.98 & $(0.96-0.99)$ & 0.021 & 0.98 & $(0.97-1.00)$ & 0.11 \\
\hline SD MBG & 1.13 & $(1.07-1.19)$ & $<0.001$ & 1.09 & $(1.02-1.17)$ & 0.009 \\
\hline \multicolumn{7}{|l|}{ Pre-lunch } \\
\hline MBG & 0.99 & $(0.87-1.02)$ & 0.87 & 1.01 & $(0.99-1.04)$ & 0.26 \\
\hline SD MBG & 1.09 & $(1.04-1.15)$ & 0.001 & 1.05 & $(0.98-1.16)$ & 0.16 \\
\hline \multicolumn{7}{|l|}{ Post-lunch } \\
\hline MBG & 0.98 & $(0.96-0.99)$ & 0.006 & 0.99 & $(0.96-1.01)$ & 0.26 \\
\hline SD MBG & 1.09 & $(1.05-1.14)$ & $<0.001$ & 1.02 & $(0.97-1.06)$ & 0.49 \\
\hline \multicolumn{7}{|l|}{ Pre-supper } \\
\hline MBG & 0.98 & $(0.97-1.00)$ & 0.11 & 1.08 & $(1.01-1.15)$ & 0.019 \\
\hline SD MBG & 1.07 & $(1.02-1.11)$ & 0.002 & 1 & $(0.95-1.06)$ & 0.92 \\
\hline \multicolumn{7}{|l|}{ Post-supper } \\
\hline MBG & 0.99 & $(0.97-1.01)$ & 0.25 & 1 & $(0.98-1.03)$ & 0.7 \\
\hline SD MBG & 1.11 & $(1.05-1.18)$ & $<0.001$ & 1.05 & $(0.99-1.13)$ & 0.11 \\
\hline \multicolumn{7}{|l|}{ Bedtime } \\
\hline MBG & 0.99 & $(0.97-1.01)$ & 0.26 & 0.99 & $(0.97-1.01)$ & 0.39 \\
\hline SD MBG & 1.11 & $(1.05-1.16)$ & $<0.001$ & 1.07 & $(1.01-1.14)$ & 0.027 \\
\hline
\end{tabular}

All models adjusted as in Table 4

MBG (AUC) relates to the AUC, while MBG relates to the arithmetic mean

Notwithstanding these reservations, few studies have evaluated the risk of hypoglycaemia in relation to markers of glycaemia in as many patients and in as much detail as the DCCT. The large number of patients $(n=1441)$ followed for a mean of 6.5 years led to the collection of 33,324 glucose profiles on which to base the data analysis. Also of relevance is the fact that the way in which pre- and postprandial samples were collected in the DCCT was not dissimilar to the way in which patients are currently recommended to self-monitor their blood glucose using glucose meters [35]. Indeed, even if patients limit themselves to pre-meal and bedtime readings, this study has found that the values obtained are still useful in predicting hypoglycaemia risk. As such, our findings would indicate that the ability of many meters to display the mean glucose of prior readings is beneficial. It has already been suggested that measures of glucose instability should also be calculated by these instruments in order to help further gauge the risk of hypoglycaemia [36, 37]. Since changes in glucose variability in this study were similarly predictive of severe hypoglycaemia as MBG, the usefulness, for patients troubled by hypoglycaemia, of calculating glucose variability (in the form of SD) would seem to have been confirmed.
Continued development of continuous glucose monitoring systems [38] has shown great potential in reducing glycaemic excursions [39] as well as exposing many limitations of conventional self-monitoring of blood glucose [40]. However, at present, this study would suggest that clinicians use all three tools $\left(\mathrm{HbA}_{1 \mathrm{c}}, \mathrm{MBG}\right.$ and glucose variability) in order assess the likelihood of hypoglycaemia in their patients. This approach may be especially clinically relevant to patients whose MBG is not entirely concordant with their $\mathrm{HbA}_{1 \mathrm{c}}$ value. A previous analysis of the DCCT dataset showed that individual patients with an MBG of, for example, $10 \mathrm{mmol} / \mathrm{l}$ can have mean $\mathrm{HbA}_{1 \mathrm{c}}$ values between 6 and $10 \%$ [12]. It would seem reasonable to suggest that patients at either end of this $\mathrm{HbA}_{1 \mathrm{c}}$ range might benefit most from additional glucose measurement, even though it has not been proven by this data analysis.

In summary, this study has established that $\mathrm{HbA}_{1 \mathrm{c}}, \mathrm{MBG}$ and glucose variability each have an independent association with an individual's risk of hypoglycaemia in type 1 diabetes. It therefore reaffirms the benefit of using all three measures of glycaemia to predict, and thereby hopefully avoid, severe hypoglycaemia. 
Acknowledgements We wish to thank the DCCT investigators for making their trial dataset public, thereby allowing independent investigators to analyse their work for the benefit of patients with type 1 diabetes.

Duality of interest The authors declare that there is no duality of interest associated with this manuscript.

\section{References}

1. The Diabetes Control and Complications Trial Research Group (1987) Diabetes Control and Complications Trial (DCCT): results of feasibility study. Diabetes Care 10:1-19

2. The Diabetes Control and Complications Trial Research Group (1993) The effect of intensive treatment of diabetes on the development and progression of long-term complications in insulin-dependent diabetes mellitus. N Engl J Med 329:977986

3. The Diabetes Control and Complications Trial Research Group (1995) The relationship of glycemic exposure (HbAlc) to the risk of development and progression of retinopathy in the diabetes control and complications trial. Diabetes 44:968-983

4. UK Prospective Diabetes Study (UKPDS) Group (1998) Intensive blood-glucose control with sulphonylureas or insulin compared with conventional treatment and risk of complications in patients with type 2 diabetes (UKPDS 33). UK Prospective Diabetes Study (UKPDS) Group. Lancet 352:837-853

5. Stratton IM, Adler AI, Neil HA et al (2000) Association of glycaemia with macrovascular and microvascular complications of type 2 diabetes (UKPDS 35): prospective observational study. BMJ 321:405-412

6. The Diabetes Control and Complications Trial Research Group (1996) The absence of a glycemic threshold for the development of long-term complications: the perspective of the Diabetes Control and Complications Trial. Diabetes 45:1289-1298

7. Cryer PE, Davis SN, Shamoon H (2003) Hypoglycemia in diabetes. Diabetes Care 26:1902-1912

8. MacLeod KM, Hepburn DA, Frier BM (1993) Frequency and morbidity of severe hypoglycaemia in insulin-treated diabetic patients. Diabet Med 10:238-245

9. Laing SP, Swerdlow AJ, Slater SD et al (1999) The British Diabetic Association Cohort Study, II: cause-specific mortality in patients with insulin-treated diabetes mellitus. Diabet Med $16: 466-471$

10. Cox DJ, Penberthy JK, Zrebiec J et al (2003) Diabetes and driving mishaps: frequency and correlations from a multinational survey. Diabetes Care 26:2329-2334

11. The Diabetes Control and Complications Trial Research Group (1997) Hypoglycemia in the diabetes control and complications trial. The Diabetes Control and Complications Trial Research Group. Diabetes 46:271-286

12. Rohlfing CL, Wiedmeyer HM, Little RR et al (2002) Defining the relationship between plasma glucose and $\mathrm{HbA}(1 \mathrm{c})$ : analysis of glucose profiles and $\mathrm{HbA}(1 \mathrm{c})$ in the diabetes control and complications trial. Diabetes Care 25:275-278

13. American Diabetes Association Workgroup on Hypoglycemia (2005) Defining and reporting hypoglycemia in diabetes: a report from the American Diabetes Association Workgroup on Hypoglycemia. Diabetes Care 28:1245-1249
14. The Diabetes Control and Complications Trial Research Group (1991) Epidemiology of severe hypoglycemia in the diabetes control and complications trial. Am J Med 90:450-459

15. Tai MM (1994) A mathematical model for the determination of total area under glucose tolerance and other metabolic curves. Diabetes Care 17:152-154

16. Moberg E, Kollind M, Lins PE, Adamson U (1993) Estimation of blood-glucose variability in patients with insulin-dependent diabetes mellitus. Scand J Clin Lab Invest 53:507-514

17. Service FJ, Molnar GD, Rosevear JW et al (1970) Mean amplitude of glycemic excursions, a measure of diabetic instability. Diabetes 19:644-655

18. Wang D, Bakhai A (2006) Clinical Trials. A practical guide to design, analysis and reporting. Remedica, London

19. Monnier L, Lapinski H, Colette C (2003) Contributions of fasting and postprandial plasma glucose increments to the overall diurnal hyperglycemia of type 2 diabetic patients: variations with increasing levels of HbA1c. Diabetes Care 26:881-885

20. Schoenfeld D (1982) Partial residual estimation for the proportional hazards regression model. Biometrika 69:239-241

21. Grambsch P, Therneau TM (1994) Proportional hazards tests and diagnostics based on weighted residuals. Biometrika 81:515-526

22. Francis B, Green M, Payne M (1994) The GLIM System. Release 4 manual. Clarendon, Oxford

23. Lawless JFW, Wigg MB, Tuli S, Drake J, Lamberti-Pasculli M. (2001) Analysis of repeated failures or durations, with application to shunt failures for patients with paediatric hydrocephalus. Applied Statistician 50:449-465

24. Fine JP (1999) Analysing competing risks data with transformation models. J R Stat Soc Ser B 61:817-830

25. Verweij P, van Houwelingen H (1993) Cross-validation in survival analysis. Stat Med 12:2305-2314

26. Efron B (2000) The bootstrap and modern statistics. J Am Stat Assoc 95:1293-1296

27. Efron B, Tibshirani R (1986) Bootstrap methods for standard errors, confidence intervals, and other measures of statistical accuracy. Stat Sci 1:54-77

28. Sauerbrei W, Schumacher M (1992) A bootstrap resampling procedure for model building: application to the Cox regression model. Stat Med 11:2093-2109

29. Kilpatrick ES, Rigby AS, Atkin SL (2006) The effect of glucose variability on the risk of microvascular complications in type 1 diabetes. Diabetes Care 29:1486-1490

30. Bolli GB (2006) Glucose variability and complications. Diabetes Care 29:1707-1709

31. Goldgewicht C, Slama G, Papoz L, Tchobroutsky G (1983) Hypoglycaemic reactions in 172 Type 1 (insulin-dependent) diabetic patients. Diabetologia 24:95-99

32. ter Braak E, Appelman A, van de Laak M et al (2000) Clinical characteristics of type 1 diabetic patients with and without severe hypoglycaemia. Diabetes Care 23:1467-1471

33. Kilpatrick ES, Rigby AS, Atkin SL (2007) Variability in the relationship between mean plasma glucose and $\mathrm{HbAlc:} \mathrm{implications}$ for the assessment of glycemic control. Clin Chem 53:897-901

34. Pedersen-Bjergaard U, Pramming S, Heller SR et al (2004) Severe hypoglycaemia in 1076 adult patients with type 1 diabetes: influence of risk markers and selection. Diabetes Metab Res Rev 20:479-486

35. American Diabetes Association (2007) Standards of Medical Care in Diabetes-2007. Diabetes Care 30:S4-S41

36. Kovatchev BP, Cox DJ, Gonder-Frederick L, Clarke WL (2002) Methods for quantifying self-monitoring blood glucose profiles exemplified by an examination of blood glucose patterns in patients with type 1 and type 2 diabetes. Diabetes Technol Ther 4:295-303 
37. Kovatchev BP, Cox DJ, Kumar A, Gonder-Frederick L, Clarke WL (2003) Algorithmic evaluation of metabolic control and risk of severe hypoglycemia in type 1 and type 2 diabetes using selfmonitoring blood glucose data. Diabetes Technol Ther 5:817828

38. Klonoff DC (2005) Continuous glucose monitoring: roadmap for 21st century diabetes therapy. Diabetes Care 28:1231-1239
39. Garg S, Zisser H, Schwartz S et al (2006) Improvement in glycemic excursions with a transcutaneous, real-time continuous glucose sensor: a randomized controlled trial. Diabetes Care 29:44-50

40. Boland E, Monsod T, Delucia M et al (2001) Limitations of conventional methods of self-monitoring of blood glucose: Lessons learned from 3 days of continuous glucose sensing in pediatric patients with type 1 diabetes. Diabetes Care 24:1858-1862 